\title{
Soybean-derived blue photoluminescent carbon dots
}

\author{
Shanshan Wang ${ }^{1,2}$, Wei Sun ${ }^{3}$, Dong-sheng Yang ${ }^{* 1}$ and Fuqian Yang ${ }^{* 2}$
}

\author{
Full Research Paper \\ Address: \\ ${ }^{1}$ Department of Chemistry, University of Kentucky, Lexington, KY \\ 40506, United States, ${ }^{2}$ Materials Program, Department of Chemical \\ and Materials Engineering, University of Kentucky, Lexington, KY \\ 40506, United States and ${ }^{3}$ College of Chemistry, Chemical \\ Engineering and Environmental Engineering, Liaoning Shihua \\ University, Fushun, Liaoning, 113001, China \\ Email: \\ Dong-sheng Yang* - Dong-Sheng.Yang@uky.edu; Fuqian Yang* - \\ fyang2@uky.edu \\ * Corresponding author \\ Keywords: \\ biomass; carbon dots; hydrothermal process; laser ablation; \\ $\mathrm{N}$-doping; photoluminescence
}

\begin{abstract}
Biomass-derived carbon dots (CDs) are biocompatible and have potential for a variety of applications, including bioimaging and biosensing. In this work, we use ground soybean residuals to synthesize carbon nanoparticles by hydrothermal carbonization (HTC), annealing at high temperature, and laser ablation (LA) in a $\mathrm{NH}_{4} \mathrm{OH}$ solution. The carbon nanoparticles synthesized with the HTC process (HTC-CDs) exhibit photoluminescent characteristics with strong blue emission. The annealing of the HTC-processed carbon particles in the range of 250 to $850{ }^{\circ} \mathrm{C}$ causes a loss of the photoluminescent characteristics of the CDs without any significant change in the microstructure (amorphous structure) of the carbon particles. The LA processing of the annealed HTC-processed carbon particles introduces nitrogen-containing surface-functional groups and leads to the recovery of the photoluminescent features that are different from those of the HTC-CDs and dependent on the fraction of nitrogen in the surface-functional groups. The photoluminescence of both the HTC-CDs and LA-CDs is largely due to the presence of N-containing surface-functional groups. The quantum yield of the LA-CDs is more constant than that of the HTC-CDs under continuous UV excitation and does not exhibit a significant reduction after $150 \mathrm{~min}$ of excitation. The methods used in this work provide a simple and green strategy to introduce $\mathrm{N}$-surface-functional groups to carbon nanoparticles made from biomass and biowaste and to produce stable photoluminescent CDs with excellent water-wettability.
\end{abstract}

\section{Introduction}

Carbon-based quantum dots, which are referred to as carbon dots (CDs) [1] and are less-toxic and ecologically friendly [2,3], have attracted great interest due to their unique properties, such as high water solubility [4], high chemical stability [5], high photostability [6], tunable excitation and emission wavelength [7], and low cost [8]. CDs have been considered as a group of 
important nanomaterials with potential applications in nanotechnology [9], electrocatalysis [10], metal-ion detection [2], thermal sensing [11], drug delivery [12], and biosensing and bioimaging [1].

Several methods are available for synthesizing CDs, including oxidation and reduction [13-15], laser ablation [16], microwave irradiation [9], pyrolysis [17], and hydrothermal treatment [18]. Some of these methods are tedious and time consuming and use strong acids and/or surface treatment to improve their water solubility and luminescence properties. Hydrothermal carbonization (HTC), which can be considered as a "green technology", has been used to produce photoluminescent CDs from biomass, including glucose, sucrose, citric acid [19], chitosan [20], orange juice [21], grass [22] and soy milk [10]. For example, Sahu et al. [21] synthesized photoluminescent CDs of $1.5-4.5 \mathrm{~nm}$ in diameter from orange juice at $120^{\circ} \mathrm{C}$. Liu et al. [22] produced photoluminescent polymer nanodots of 3-5 nm in diameter by using grass as a precursor at $180{ }^{\circ} \mathrm{C}$, and Zhu et al. [10] synthesized bifunctional blue-emission carbon nanodots with diameters of $13-40 \mathrm{~nm}$ from soy milk also at $180^{\circ} \mathrm{C}$.

Laser ablation in liquid (LAL) has been used to produce nanomaterials with special morphologies, microstructures, and phases and with various functionalized nanostructures [23-25]. For example, carbon-based nanoparticles with fewer sideproducts have been synthesized from glassy carbon [16], graphite [26], polymethyl methacrylate (PMMA) [27], and a graphite-cement mixture [6] via LAL in various liquids.

In general, there are three major mechanisms contributing to the photoluminescence (PL) of CDs: 1) size-dependent bandgap (quantum confinement), 2) surface states consisting of functional groups [28], and 3) molecular state (domain size in CDs) $[29,30]$. Other factors, such as conjugated $\pi$-domains, molecular states, and crosslink-enhanced emission, need to be taken into account in the understanding of the PL emission of CDs. Also, the PL behavior of CDs varies with $\mathrm{pH}$ and temperature [18]. Wang et al. [18] studied the fluorescence of the CDs made from glucose with glutathione in a temperature range of 15 to $90{ }^{\circ} \mathrm{C}$ and observed the change of the color from dark blue to light blue and the quenching of the fluorescence at high temperatures. They attributed the fluorescent quenching to the aggregation of CDs, which increased the particle size from $2.6 \pm 0.2 \mathrm{~nm}$ to $4.4 \pm 0.2 \mathrm{~nm}$. However, there are few studies in the literature focusing on the comparison of the PL behavior of CDs made from the same biomass precursor with different synthetic or processing methods; such studies would provide insight into the CD formation and PL mechanisms [31,32]. Using fluorescent $\mathrm{N}$-doped $\mathrm{CDs}$, which were made from grinding soybean via a pyrolysis process at $200{ }^{\circ} \mathrm{C}$ for $3 \mathrm{~h}$ under argon atmosphere, $\mathrm{Xu}$ et al. [31] observed blue emission with maximum emission of $3.17 \%$ quantum yield at $\approx 405 \mathrm{~nm}$ under $330 \mathrm{~nm}$ excitation. Meng et al. [32] synthesized green-emitting CDs by a hydrothermal process from soybean powder at $170{ }^{\circ} \mathrm{C}$ and obtained the highest quantum yield of $7.14 \%$ for the greenemitting CDs prepared with a processing time of $16 \mathrm{~h}$.

Considering the potential applications of CDs in bioimaging and biosensing, we synthesize biocompatible CDs from soybean residuals using two strategies. The first strategy uses a one-step HTC process to produce CDs directly from the soybean residuals, and the second one uses multiple steps to produce $\mathrm{CDs}$ from the same soybean precursors, which involves the HTC treatment, high-temperature annealing, and LAL processing, sequentially. The purpose of the LAL processing is to introduce $\mathrm{N}$-containing functional groups onto the surface of carbon nanoparticles and to recover the PL of carbon nanoparticles/CDs that was quenched by the high-temperature annealing. Both methods can be categorized as top-down methods in contrast to bottom-up methods. The PL characteristics of the CDs produced by both methods are analyzed, and the PL mechanisms of the CDs are discussed. The strategies developed in this work offer simple and effective means for producing biocompatible CDs from biomass and biowaste and manipulating their PL characteristics.

It is worth mentioning that we [33] previously studied the electrochemical performance of carbon particles of micrometer size, which were synthesized from the soybean residuals via hydrothermal carbonization and high-temperature annealing in nitrogen. In contrast to the analysis of the electrochemical performance of large carbon particles of micrometer size [33], this work is focused on the optical characteristics of nanometersized CDs, which are synthesized by two different approaches. One is similar to the one used for the electrochemical study and the other uses multiple processes including annealing in argon. Note that filtration is needed to obtain carbon nanoparticles from the carbonized soybean residual.

\section{Experimental Hydrothermal carbonization}

Following the approach in Wang et al. [33], we hydrothermally carbonized soybean residual. Briefly, a suspension consisting of $\approx 40 \mathrm{~g}$ of ground soybean residual and $\approx 5 \mathrm{~mL}$ of $1 \mathrm{wt} \% \mathrm{H}_{2} \mathrm{SO}_{4}$ aqueous solution was prepared and stirred ultrasonically. The suspension was transferred into a Teflon-lined autoclave, which was then placed in an oven for the HTC processing at $200{ }^{\circ} \mathrm{C}$ for $20 \mathrm{~h}$. After the Teflon-lined autoclave was cooled to room temperature in air, filtration with filter paper of $10 \mu \mathrm{m}$ pore size was performed to separate the HTC-produced mixture. The filtrate was further filtered with filter paper of $450 \mathrm{~nm}$ pore size. 
The material collected after the filtration was dried at $60{ }^{\circ} \mathrm{C}$ in a vacuum oven for $24 \mathrm{~h}$, and the final product was named as HTC-CDs.

\section{High-temperature annealing}

The high-temperature annealing was performed in a horizontal tube furnace under the flow of argon gas. A quartz boat loaded with HTC-processed carbon particles was placed in the tube around the center of the hot zone. The tube furnace was first flushed at room temperature with argon gas at a flow rate of 300 SCCM (standard cubic centimeters per minute) for $30 \mathrm{~min}$, then heated up to a pre-set annealing temperature of $850^{\circ} \mathrm{C}$ at a ramp rate of $20^{\circ} \mathrm{C} / \mathrm{s}$ under the flow of argon gas at a flow rate of $50 \mathrm{SCCM}$, and finally maintained at $850{ }^{\circ} \mathrm{C}$ for $2 \mathrm{~h}$ to anneal the HTC-processed carbon particles. After the annealing, the furnace/system was reduced to room temperature in air. The black carbon powders, which formed in the quartz boat, were collected, and the carbon nanoparticles obtained after filtration were named as annealed-CDs.

\section{Laser ablation in $\mathrm{NH}_{4} \mathrm{OH}$ solution}

Figure 1 illustrates the process for the synthesis of CDs from ground soybean residual and the setup for the laser ablation of the annealed-HTC carbon particles in $\mathrm{NH}_{4} \mathrm{OH}$ aqueous solution. Using a prism and an optical lens shown in Figure 1, the beam size of the laser was adjusted to $\approx 2 \mathrm{~mm}$. The laser wave- length was $532 \mathrm{~nm}$, the pulse frequency was $50 \mathrm{~Hz}$, and the dwell was 1-2 ns.

A mixture consisting of $\approx 0.06 \mathrm{~g}$ annealed-HTC carbon particles and $0.012 \mathrm{~g}$ Teflon powder was heated to $110{ }^{\circ} \mathrm{C}$ and maintained at $110{ }^{\circ} \mathrm{C}$ for $1 \mathrm{~h}$. A mechanical press of the heated mixture at 6000 psi for $5 \mathrm{~min}$ led to the formation of a circular pellet of $\approx 1.27 \mathrm{~cm}$ in diameter and $\approx 1 \mathrm{~mm}$ in thickness. The circular pellet was transferred to a self-made vial with a quartz window for laser ablation, and $\approx 3 \mathrm{~mL} \mathrm{NH}_{4} \mathrm{OH}$ aqueous solution was added to the vial to submerse the pellet to a depth of $2 \mathrm{~cm}$. A quartz window lid was used to minimize the loss of the $\mathrm{NH}_{4} \mathrm{OH}$ solution during the laser ablation. The vial was placed on the top of the rotation stage. The rotation of the vial ensured that each laser pulse impinged on a fresh surface of the pellet.

The LAL processing of the annealed-HTC carbon particles in the $\mathrm{NH}_{4} \mathrm{OH}$ solution was performed with a pulse energy of $100 \mathrm{~mJ}$ for $1 \mathrm{~h}$. After the LAL processing, the liquid that remained in the vial was collected and filtered with a $0.45 \mu \mathrm{m}$ syringe prior to analysis. After all solvents were evaporated, $\approx 4 \mathrm{~mL}$ of DI (deionized) water was added to the vial to form a suspension, which was sonicated for $1 \mathrm{~h}$ at room temperature. $\mathrm{NH}_{4} \mathrm{OH}$ solutions of concentrations of $5 \%, 15 \%, 20 \%$ and $30 \%$ in volume were used in the LAL processing. The obtained LA

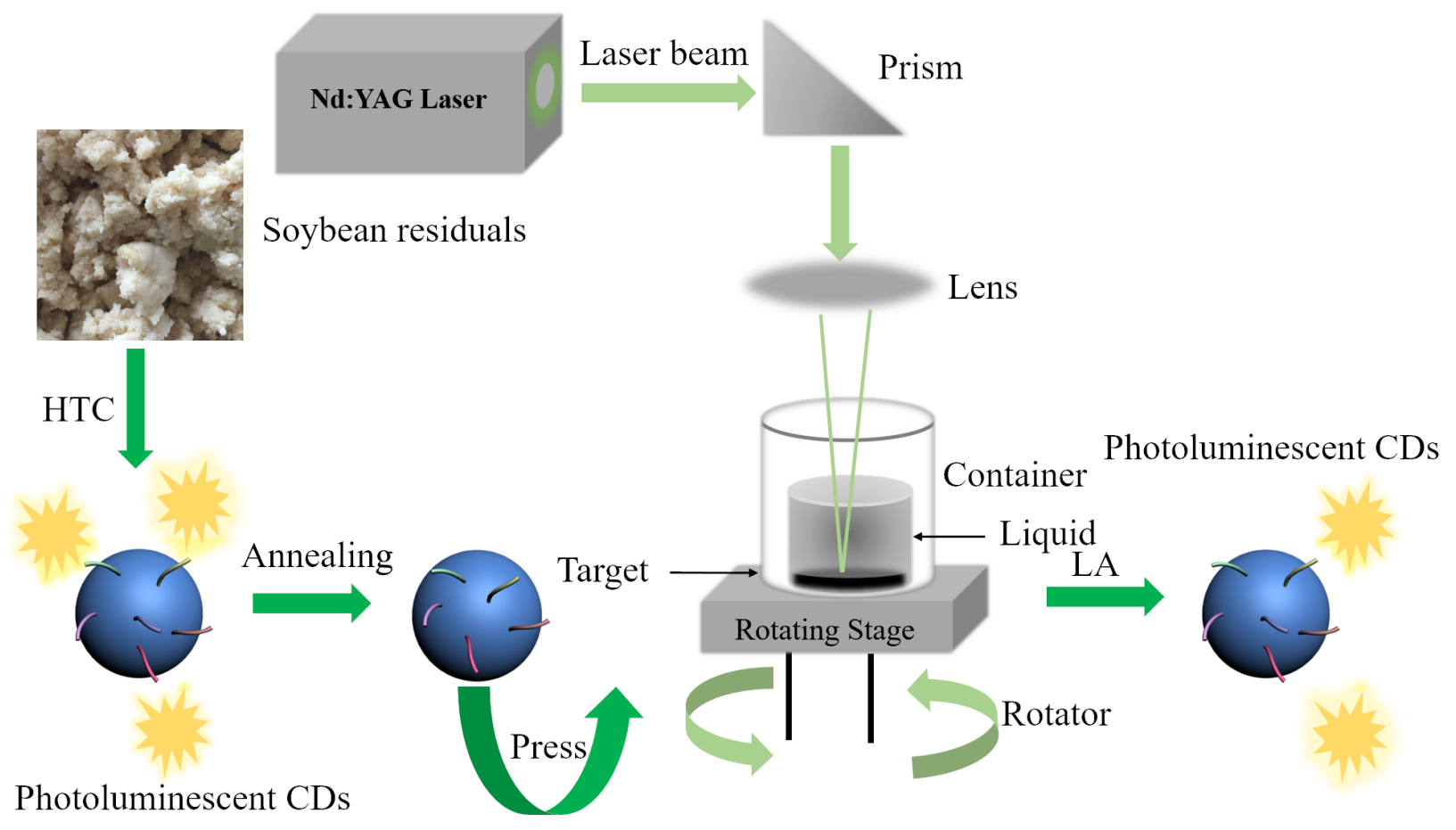

Figure 1: Schematic of the setup for laser ablation in liquid. 
samples were named as LA-CDs- $\mathrm{x} \%$ with $\mathrm{x}$ representing the concentration of the $\mathrm{NH}_{4} \mathrm{OH}$ solution.

The control experiment of the laser-ablation of Teflon was performed following the same process as described above without any carbon materials. A circular Teflon pellet of $\approx 1.27 \mathrm{~cm}$ in diameter and $\approx 1 \mathrm{~mm}$ in thickness was prepared by the press of $\approx 0.06 \mathrm{~g}$ of pure Teflon powder at $110^{\circ} \mathrm{C}$ under a compressive stress of $6000 \mathrm{psi}$ for $5 \mathrm{~min}$. The laser ablation of the Teflon pellet was conducted in a container with $3 \mathrm{~mL}$ of $\mathrm{NH}_{4} \mathrm{OH}$ for $1 \mathrm{~h}$.

\section{Materials characterization}

The morphology and microstructure of the prepared carbon nanoparticles were characterized on a transmission electron microscope (TEM) (JEOL 2010F). ImageJ software was used to analyze the TEM images and to determine the distribution of particle sizes for the calculation of average particle size. The X-ray photoelectron spectroscopy (XPS) analysis of the prepared carbon nanoparticles was conducted on a Thermo Scientific K-Alpha X-ray photoelectron spectrometer to determine the chemical states of elements in the prepared carbon nanoparticles.

The PL characteristics of the prepared carbon nanoparticles were characterized on a fluorometer (HORIBA, Fluoromax-3) equipped with a xenon lamp of $120 \mathrm{~W}$ as the light source. The absolute quantum yield (QY) was measured on a second fluorometer (Horiba Fluoromax-4) equipped with an integrating sphere. A quartz cubic cell with a $1 \mathrm{~cm}$ light path, which was filled with a suspension consisting of the prepared carbon nanoparticles, was used in UV-vis absorption measurements using a UV-visible spectrophotometer (Thermal Scientific Evolution 201). The Fourier-transform infrared spectroscopy (FTIR) analysis of the prepared carbon nanoparticles was conducted on a Fourier transform infrared instrument (Nicolet iS50) in the wavenumber range of 400 to $4000 \mathrm{~cm}^{-1}$ at a resolution of $4 \mathrm{~cm}^{-1}$.

\section{Results}

Figure 2 shows TEM images of the soybean-derived nanoparticles and the corresponding size distribution. All the nanoparticles are of polygonal shape (Figure $2 \mathrm{a}-\mathrm{c}$ ), suggesting that the annealing at high temperatures and the laser ablation did not cause any significant changes to the morphology of the nanoparticles. The selected area electron diffraction (SAED) patterns embedded in the figures reveal that all the nanoparticles are amorphous. The EDS and XPS analyses of the HTC-CDs shown in Figure S1 and Table S1 in Supporting Information File 1 confirm that the main component of the HTC-CDs is carbon. The annealing at the temperature of $850{ }^{\circ} \mathrm{C}$ did not cause the conversion of amorphous carbon nanoparticles to nanocrystals, and the LAL processing of the annealed-HTC carbon particles also produced amorphous carbon nanoparticles.
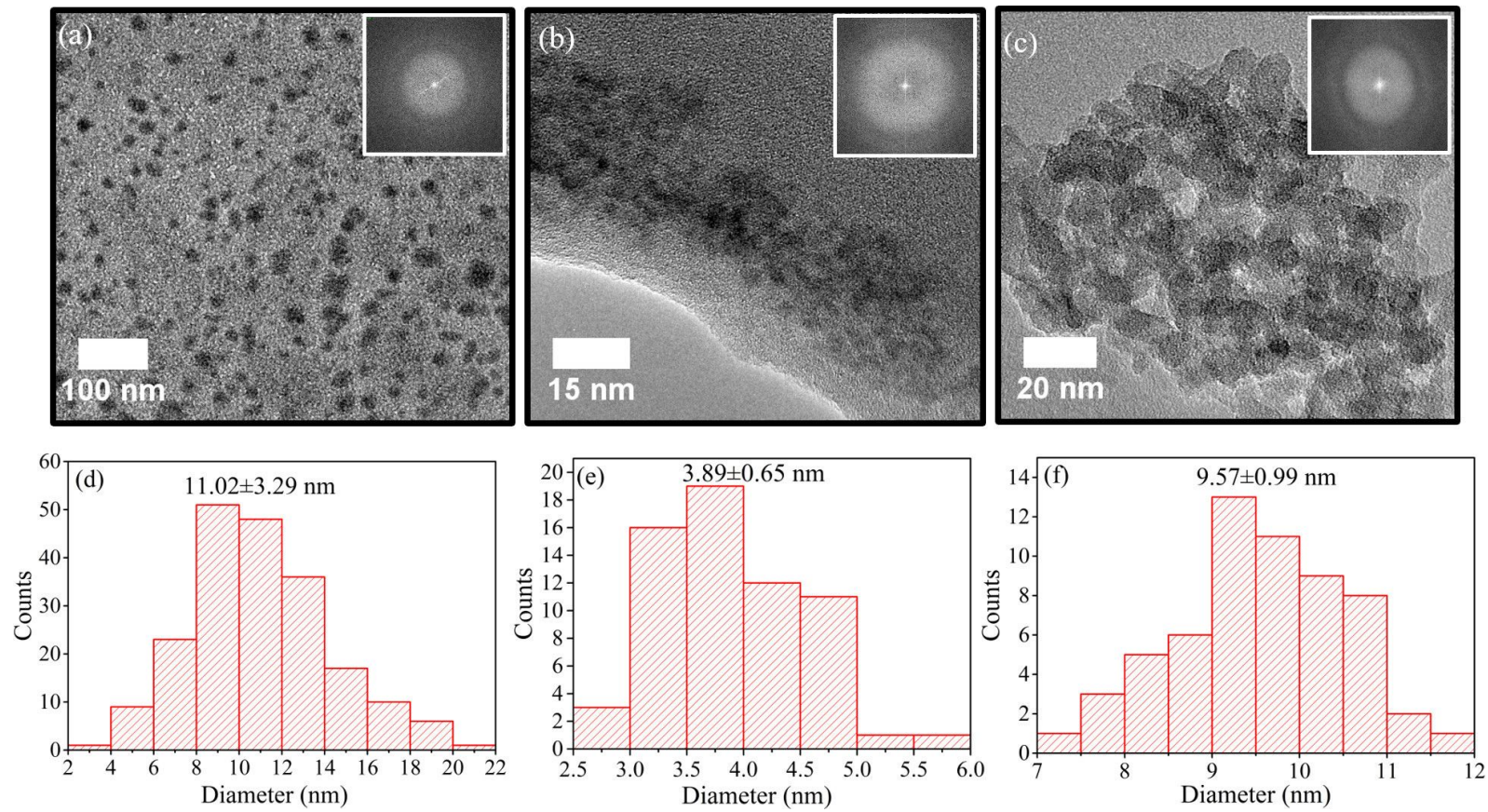

Figure 2: TEM images of soybean-derived nanoparticles: (a) HTC-CDs, (b) annealed-CDs (annealing temperature: $850{ }^{\circ} \mathrm{C}$ ), and (c) LA-CDs- $10 \%$; the size distribution of soybean-derived nanoparticles: (d) HTC-CDs, (e) annealed-CDs, and (f) LA-CDs- $10 \%$. 
The size distribution of the soybean-derived nanoparticles is depicted in Figure 2d-f, which was determined from the TEM images via the software of ImageJ. Slight differences are observed in the shapes of the size distribution among the HTCCDs, annealed-CDs and LA-CDs- $10 \%$. The histogram of the HTC-CDs has a long tail in the distribution; the histogram of the annealed-CDs is close to Gaussian distribution; and the histogram of the LA-CDs- $10 \%$ has a long front in the distribution. The mechanism for the differences in the shapes of the size distribution is unclear and might be due to the effects of high-temperature annealing and laser ablation on the motion of atoms. From the size distribution, we obtain the average particle sizes of the soybean-derived nanoparticles as $11.02 \pm 3.29$, $3.89 \pm 0.65$ and $9.57 \pm 0.99 \mathrm{~nm}$ for the HTC-CDs, annealedCDs and LA-CDs- $10 \%$, respectively. The observed average particle sizes are different from the amorphous CDs of $2.6 \pm 0.2 \mathrm{~nm}$ made from glucose with glutathione in a temperature range of 15 to $90^{\circ} \mathrm{C}$ by Wang et al. [18].

Figure 3a-c shows the PL spectra of the soybean-derived CDs. The HTC-CDs exhibited strong emission under the irradiation of UV and visible light in the wavelength range of $250 \mathrm{~nm}$ to $480 \mathrm{~nm}$ (Figure 3a), indicating the broad PL characteristics of the HTC-CDs. The broad multicolor emission can be attributed to the heterogeneity of CDs due to structural variety [1], includ- ing surface-functional groups and domain structures, and to the broad absorption ranging from UV to visible light [34]. There are three strong emission peaks at 423, 440, and $452 \mathrm{~nm}$ for the HTC-CDs, which are excited by the UV-vis light at the wavelengths of 330,360 and $390 \mathrm{~nm}$.

The sharp peaks presented in the PL spectrum of the annealedCDs (Figure 3b), which are significantly different from those for the HTC-CDs and LA-CDs- $10 \%$, are due to the Raman scattering of the water [35]. The annealed-CDs show no PL under irradiation with UV-vis light. Note that the sharp peaks in Figure $3 \mathrm{~b}$ represent the Raman scattering of water (solvent) only, indicating that there is no photoluminescence emission from the annealed-CDs under excitation at various wavelengths. The Raman scattering of the annealed CDs has a relatively low yield. The Raman peaks can be only observed when the gain or slit bandwidth of the instrument is increased to compensate for the low fluorescence signal.

In contrast to the annealed-CDs, the LA-CDs- $10 \%$, which are produced by the laser ablation of the annealed-CDs, exhibited strong emission under the irradiation of UV-vis light in the range of 250 to $480 \mathrm{~nm}$. For example, the wavelength and full width at half maximum (FWHM) of the maximum emission peak are $459 \mathrm{~nm}$ and $91 \mathrm{~nm}$, respectively, under irradiation of
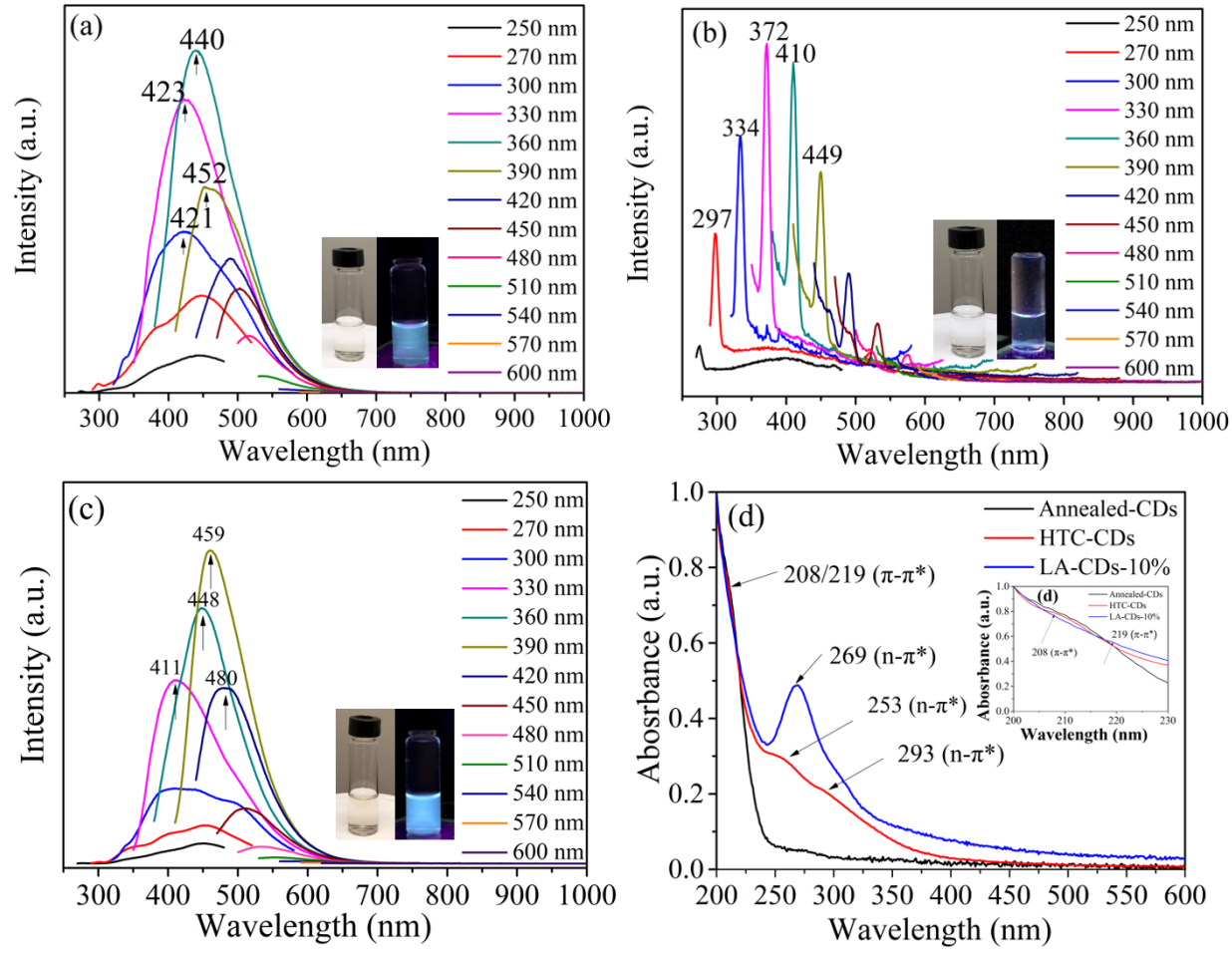

Figure 3: Photoluminescence spectra of: (a) HTC-CDs, (b) annealed-CDs, and (c) LA-CDs-10\%; (d) UV-vis absorbance spectra of different soybeanderived CDs. 
390 nm light. Comparing the PL spectrum of the LA-CDs-10\% with that of the HTC-CDs, we note a blue shift from $423 \mathrm{~nm}$ emission of the HTC-CDs to $411 \mathrm{~nm}$ emission of the LA-CDs$10 \%$ with $330 \mathrm{~nm}$ excitation.

The difference in the PL characteristics can also be observed from the insets in Figure $3 \mathrm{a}-\mathrm{c}$. The color of the aqueous solutions of both the HTC-CDs and LA-CDs-10\% is light-yellow under white light and blue under UV light irradiation of $365 \mathrm{~nm}$. However, there is no difference in color for the aqueous suspension of the annealed-CDs under white light and $365 \mathrm{~nm}$ excitation.

The UV-vis spectra of the HTC-CDs, annealed-CDs and LA-CDs- $10 \%$ are depicted in Figure 3d. There are three peaks at 208, 253 and $293 \mathrm{~nm}$ for the HTC-CDs. The peak at $208 \mathrm{~nm}$ is from the $\pi-\pi^{*}$ transition of the conjugated $\mathrm{C}=\mathrm{C}$ bond on the backbone of carbon [36], and the broad absorbance peaks at 253 and $293 \mathrm{~nm}$ are from the $n-\pi^{*}$ transition of the carbonyl and other oxygen or nitrogen-containing groups [37]. There is no visible peak for the annealed-CDs, which exhibited continuous, weak absorbance in the wavelength range of 200 to $600 \mathrm{~nm}$. Such a result suggests that the annealed-CDs are conductive and the corresponding bandgap is zero [38].

For the LA-CDs- $10 \%$, there is a small shift of $219 \mathrm{~nm}$ for the peak corresponding to the $\pi-\pi^{*}$ transition and an increase in the intensity for the peak corresponding to the $n-\pi^{*}$ transition. The strong and broad absorption band is over the range of 240 to $350 \mathrm{~nm}$ with a peak at $269 \mathrm{~nm}$, which can be ascribed to the complex transitions on the surface from the $n-\pi^{*}$ transitions in the groups of $\mathrm{C}=\mathrm{O}$ and/or $\mathrm{C}=\mathrm{OOH}[1,10,15]$. The long tail extending to the visible spectrum can be attributed to the amino groups on the surface of the CDs [39]. Note that the LA-CDs$\mathrm{x} \%$ produced from the $\mathrm{LAL}$ processing of the annealed-CDs in the $\mathrm{NH}_{4} \mathrm{OH}$ solutions of different concentrations also exhibited strong absorption near $270 \mathrm{~nm}$, which is attributed to $n-\pi^{*}$ transitions, as shown in Figure S4f in Supporting Information File 1. The significant differences in the wavelength and intensity of the $n-\pi^{*}$ transition between the HTC-CDs and the LA-CDs- $10 \%$ suggest that the functional groups and the fractions of the functional groups on the HTC-CDs are significantly different from those on the LA-CDs-10\%.

In summary, all three CDs exhibit strong $\pi-\pi^{*}$ absorption; the HTC-and LAL-CDs possess strong $n-\pi^{*}$ absorption, while there is no significant $n-\pi^{*}$ absorption from the annealed-CDs. Coupling the UV-vis absorption spectra with the PL spectra, we suggest that the observed PL originates from excited states produced by the $n-\pi^{*}$ excitation or from functionalized surface groups.
The time-correlated single photon counting (TCSPC) lifetime measurements were performed under $393 \mathrm{~nm}$ irradiation, and the emission was recorded at 440, 452, and $459 \mathrm{~nm}$. The HTCCDs exhibited the strongest emission at $440 \mathrm{~nm}$, the LA-CDs$10 \%$ exhibited the strongest emission at $459 \mathrm{~nm}$, and both exhibited moderate emission at $452 \mathrm{~nm}$. The instrument response function was determined from the analysis of the scattering of a Ludox solution at $393 \mathrm{~nm}$ excitation.

Figure 4a,b shows the PL decay curves of the HTC-CDs at $440 \mathrm{~nm}$ emission and the LA-CDs-10\% at $459 \mathrm{~nm}$ emission. Assuming that the PL decay curves can be described by a tripleexponential function [38]

$$
N(t)=A+\sum_{i=1}^{3} B_{i} e^{-t / \tau_{i}}
$$

where $N(t)$ is the number of the photons emitted at time $t, A$ represents the baseline/noise level, $B_{i}(i=1,2,3)$ are proportionality constants for the corresponding decay functions, and $\tau_{i}$ is the corresponding lifetime. Using Equation 1 to fit the PL decay curves in Figure $4 a, b$, we obtain the lifetimes of $\tau_{i}$ and the constants of $B_{i}$. The fitting curves are included in the corresponding figures. It is evident that Equation 1 is appropriate to describe the 440 and $459 \mathrm{~nm}$ PL-decay behavior of the HTCCDs and the LA-CDs- $10 \%$, respectively.

Table 1 lists the lifetimes and the corresponding contributions obtained from the curve fitting. It is evident that the PL decays of both the HTC-CDs and LA-CDs- $10 \%$ consist of three rate processes with the fastest one, $\tau_{1}$, attributed to the intrinsic state of the CDs, and two slower processes, $\tau_{2}$ and $\tau_{3}$, attributed to the decays of the extrinsic states associated with the surfacefunctional groups on the CDs $[38,40]$. According to Table 1 , the slower process, $\tau_{2}$, contributes more than $50 \%$ to the PL decay.

Figure 5 shows the temporal variations of the QYs of the HTCCDs under $360 \mathrm{~nm}$ continuous excitation and the LA-CDs- $\%$ under $390 \mathrm{~nm}$ continuous excitation. Each measurement took about $30 \mathrm{~min}$. The HTC-CDs displayed the largest QY initially, and the QY decreased gradually with the increase of the excitation time to $35.2 \%$ of the initial QY after continuous excitation of $150 \mathrm{~min}$. Such behavior might be attributed to photobleaching associated with photoinduced changes in the structure of the functional groups on the surface of the CDs [41].

In contrast to the temporal variation of the QY of the HTCCDs, the QY of the LA-CDs- $\%$ is much more stable under $390 \mathrm{~nm}$ excitation and did not exhibit a significant reduction over the $150 \mathrm{~min}$ of excitation. For the LA-CDs- $\mathrm{x} \%$ with $\mathrm{x}=5$, 

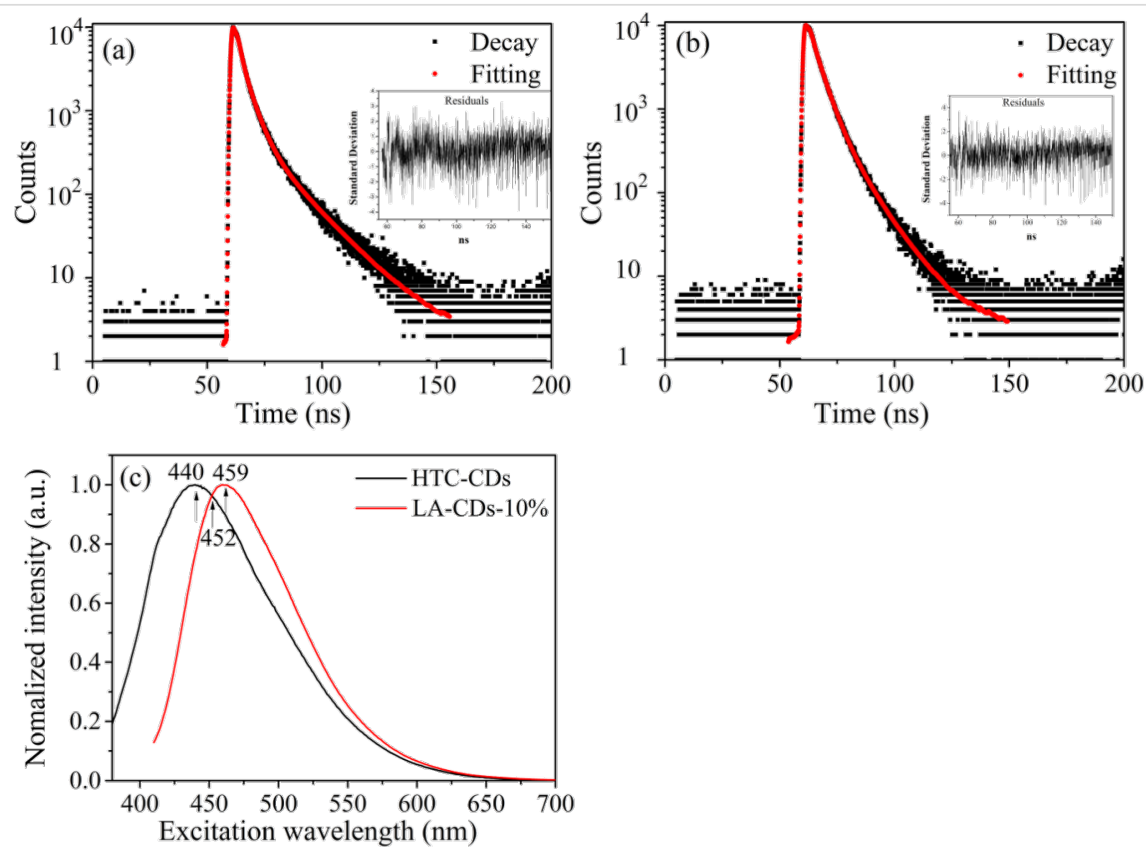

Figure 4: TCSPC lifetime curves under $393 \mathrm{~nm}$ excitation: (a) HTC-CDs at $440 \mathrm{~nm}$ emission, and (b) LA-CD-10\% at $459 \mathrm{~nm}$ emission (the red lines represent the fitting curves, and the insets depict the residues for the fittings.); (c) overlaid emission spectra of the HTC-CDs and LA-CDs- $10 \%$ under $393 \mathrm{~nm}$ excitation.

Table 1: Lifetimes $\left(\mathrm{T}_{1}, \mathrm{~T}_{2}\right.$ and $\left.\mathrm{T}_{3}\right)$ at a given emission wavelength $\left(\lambda_{\mathrm{em}}\right)$ and the relative ratios $\left(R_{i}=B_{i} /\left(B_{1}+B_{2}+B_{3}\right)\right)(\%)$ for the HTC-CDs and LA-CDs- $10 \%$ under $393 \mathrm{~nm}$ excitation.

\begin{tabular}{|c|c|c|c|c|c|c|c|}
\hline$\lambda_{\mathrm{ex}}=393 \mathrm{~nm}$ & $\lambda_{\mathrm{em}}(\mathrm{nm})$ & $\mathrm{T}_{1}(\mathrm{~ns})$ & $R_{1}(\%)$ & $\mathrm{T}_{2}(\mathrm{~ns})$ & $R_{2}(\%)$ & $\mathrm{T}_{3}(\mathrm{~ns})$ & $R_{3}(\%)$ \\
\hline \multirow[t]{3}{*}{ HTC-CDs } & 440 & $1.21(3)$ & 28.6 & $4.24(4)$ & 52.8 & $15.0(1)$ & 18.6 \\
\hline & 452 & $1.05(3)$ & 24.4 & $4.23(4)$ & 55.0 & $13.57(8)$ & 20.6 \\
\hline & 459 & $1.14(4)$ & 24.6 & $4.41(3)$ & 55.1 & $14.01(7)$ & 20.3 \\
\hline \multirow[t]{3}{*}{ LA-CDs-10\% } & 440 & $0.74(4)$ & 14.0 & $4.13(3)$ & 65.4 & $10.58(7)$ & 20.6 \\
\hline & 452 & $0.76(4)$ & 12.3 & $4.18(4)$ & 64.9 & $10.31(7)$ & 22.8 \\
\hline & 459 & $1.01(6)$ & 12.2 & $4.38(3)$ & 66.8 & $10.82(7)$ & 21.0 \\
\hline
\end{tabular}

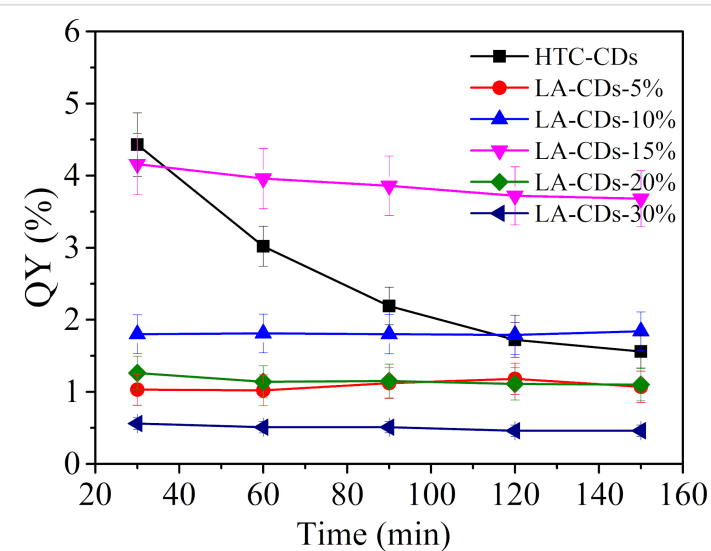

Figure 5: Temporal evolution of the quantum yields for the HTC-CDs under $360 \mathrm{~nm}$ excitation and the LA-CDs- $x \%$ under $390 \mathrm{~nm}$ excitation. The fluorescence intensity was calculated by integrating over the wavelength range of 340-700 nm for the HTC-CDs and 370-760 nm for the LA-CDs- $x \%)$.
10, 20, and 30, the QYs remained approximately unchanged. The LA-CDs-15\% displayed the largest QY among the LA-CDs, which is compatible with the largest QY of the HTCCDs and shows only $11.5 \%$ decrease after the $150 \mathrm{~min}$ of irradiation. The mecahnisms for such behavior are unclear but might be due to the relatively uniform sizes of the CDs and/or the strong bonding between the functional groups and the CDs after the LAL processing.

\section{Discussion}

It is known that three controlling mechanisms determine the PL characteristics: 1) the domain size in CDs (molecular state), 2) the functional groups on the surface of CDs (surface state), and 3 ) the quantum confinement effect (size dependence). From Figure 2, we note that the average particle size of the CDs is $11.02 \pm 3.29$ and $9.57 \pm 0.99 \mathrm{~nm}$ for the HTC-CDs and LA-CDs- $10 \%$, respectively, and the average particle size of the 
annealed-CDs is $3.89 \pm 0.65 \mathrm{~nm}$. There is only about $15 \%$ difference in the average particle size of the HTC-CDs and LA-CDs- $10 \%$, and the average particle size of the annealedCDs is significantly smaller than both the HTC-CDs and LA-CDs- $10 \%$. However, the annealed-CDs did not exhibit any PL. All of these results suggest that the size effect (quantum confinement effect) is negligible. The PL characteristics of the soybean-derived CDs are dependent on the domain size in CDs (molecular state) and the functional groups on the surface of CDs (surface state).

Table 2 summarizes the PL characteristics of the HTC-CDs, annealed-CDs and LA-CDs-10\% under 330, 360 and $390 \mathrm{~nm}$ excitation, respectively. All the annealed-CDs in the annealing temperature range of 250 to $850{ }^{\circ} \mathrm{C}$ did not exhibit any PL characteristics under excitation at any of the three wavelengths. With the annealing temperature in the range of 250 to $850{ }^{\circ} \mathrm{C}$, there is no significant change in the microstructure (amorphous structure) of carbon nanoparticles, suggesting that annealing did not likely cause any significant changes to the domain sizes in the HTC-CDs. Note that the annealing did cause the change in the size distribution of the carbon nanoparticles, as revealed in Figure 2e. Thus, it is the functional groups on the surface of the CDs that play the key role in the light emission of the soybeanderived CDs under the excitation of UV light.

Comparing the PL characteristics of the HTC-CDs with those of the LA-CDs- $10 \%$, we note the differences in the emission wavelength and the FWHM. Such differences reveal that the functional groups on the surface of the HTC-CDs are likely different from those on the surface of the LA-CDs- $10 \%$. Annealing the HTC-CDs damaged/destroyed the surface structures/function groups, resulting in the complete loss of the PL characteristics. The LAL processing of the annealed-HTC carbon particles in the $\mathrm{NH}_{4} \mathrm{OH}$ aqueous solution introduced "new" functional groups to the surface of the CDs, leading to the "rebirth" of the PL characteristics. It is interesting to note that there are large fluctuations in the FWHM for the LA-CDs-10\%, which is likely attributed to the fluctuations of the bandgap associated with the functional groups and the disorder of crystallinity introduced by the LAL processing.

According to $\mathrm{Yu}$ et al. [42], the emission peak of CDs can be fitted with a two-Gaussian function, associated with the "core" state and "surface" state, as shown schematically in Figure 6. From Figure 3, we note that the strongest emssion is at $440 \mathrm{~nm}$ for the HTC-CDs and $459 \mathrm{~nm}$ for the LA-CDs-10\%. From Figure 6, we note that both peaks indeed can be fitted with a two-Gassian function, respectively. The fitting results reveal that the $440 \mathrm{~nm}$ emission peak of the HTC-CDs can be fitted by a two-Gaussian function: one with a high energy band (the "core band") has a peak at $430 \mathrm{~nm}$ and a FWHM of $69 \mathrm{~nm}$, and the other with a low high energy band (the "surface" band) has a peak at $478 \mathrm{~nm}$ and a FWHM of $118 \mathrm{~nm}$; and the $450 \mathrm{~nm}$ emssion peak of the LA-CDs- $10 \%$ can be fitted by a twoGaussian function: the "core" band has a peak at $442 \mathrm{~nm}$ and a FWHM of $83 \mathrm{~nm}$, and the "surface" band has a peak at $488 \mathrm{~nm}$ and a FWHM of $124 \mathrm{~nm}$.

By integrating both the "core" band and the "surface" band, respectively, we obtain the area ratios of the "surface" band to the "core" band as 1.6 for the HTC-CDs and 1.0 for the LA-CDs$10 \%$. Such a difference in the area ratios (1.6 vs 1.0$)$ reveals the important role of the "surface" states and surface-functional groups in controlling the PL characteristics of the soybeanderived CDs. The FWHM difference between the strongest emission peaks of the HTC-CDs and LA-CDs- $10 \%$ is likely attributed to the difference in the "surface" states and surfacefunctional groups.

Two possibile mechanisms contribute to the loss of the PL characteristics of the annealed-CDs: the damage/destruction of the "surface" states/functional groups and the irreversible change in the energy gap induced by the annealing. It is known that the temperature dependence of the energy gap for the fluoresence of CDs can be expressed as [42]

Table 2: PL characteristics of the synthesized CDs. ${ }^{a}$

\section{HTC-CDs}

Excitation wavelength Emission peak (nm) (nm)

330

360

390

QY (\%)

$423 \pm 3$

$440 \pm 1$

$452 \pm 3$

4.46
Annealed-CDs

FWHM (nm)

129

109

109
Emission peak (nm)

NA

NA

NA

NA
LA-CDs-10\%

Emission peak (nm) FWHM

(nm)

122

203

91

${ }^{\mathrm{a}} \mathrm{FWHM}=$ full width at half maximum, NA = not available. 


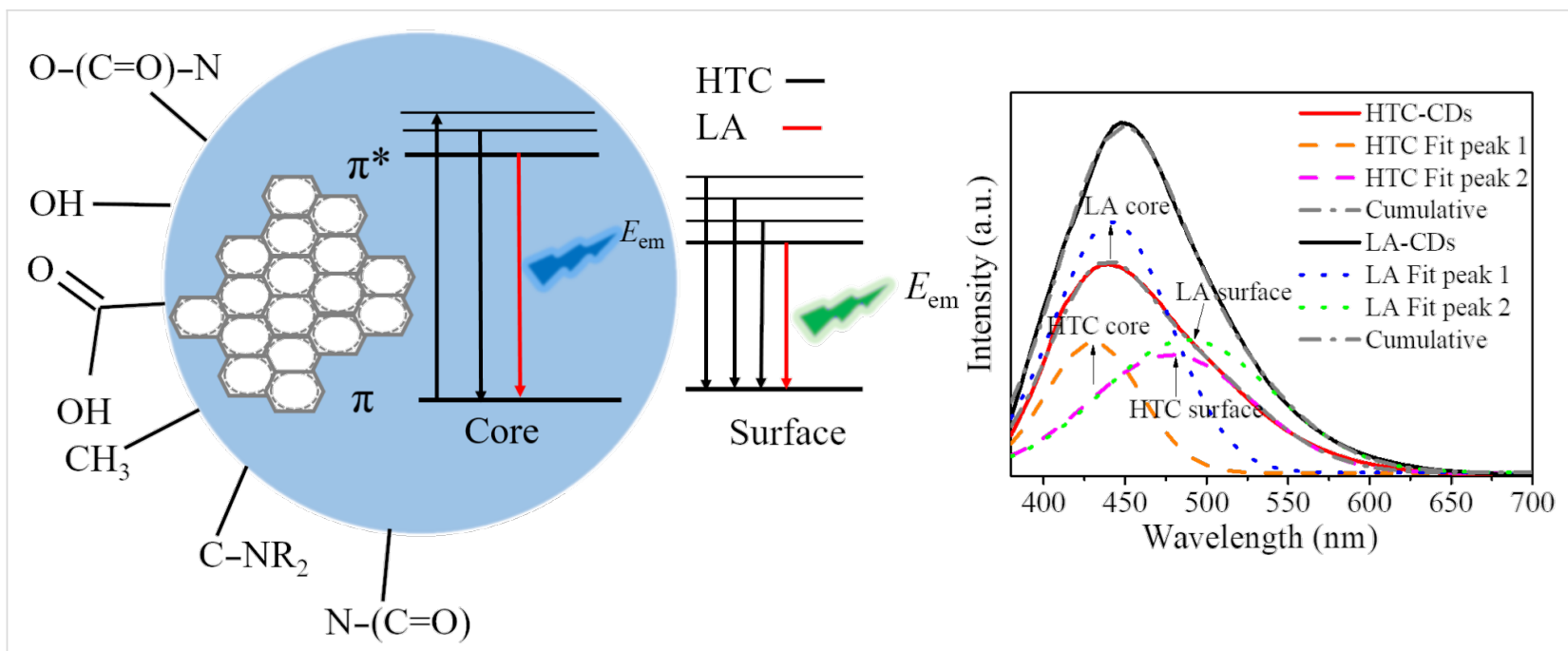

Figure 6: Schematic of the bandgaps of CDs under $360 \mathrm{~nm}$ excitation and the deconvolution bands (fitted with a two-Gassian function).

$$
E_{\mathrm{g}}(T)=E_{\mathrm{g}}(0)-2 S<h \omega>\left(e^{<h \omega>/ k T}-1\right)^{-1}
$$

where $E_{\mathrm{g}}(T)$ is the energy gap at temperature $T, S$ is the Huang-Rhys factor representing the coupling strength between exciton and phonon, $\langle h \omega\rangle$ is the phonon energy, and $k$ is the Boltzmann constant. It is evident that increasing temperature leads to the decrease of the energy gap. The CDs become conductive at temperatures larger than the critical temperture and lose the PL charactersistic, as demonstrated by the annealed-CDs due to the irreversible change in the energy gap at high temperatures.

The PL characteristics of CDs depend on the structure and composition of the CDs, as shown by the FTIR spectra of the HTCCDs, annealed-CDs, and LA-CDs-10\% (Figure 7). The FTIR spectrum of the HTC-CDs is similar to that of LA-CDs- $10 \%$, suggesting the presence of similar chemical-bonding structures. For example, both CDs possess the bonds of $\mathrm{O}-\mathrm{H}$ and $\mathrm{N}-\mathrm{H}$ stretching vibration at $3344 \mathrm{~cm}^{-1}$ and $3366 \mathrm{~cm}^{-1}[43,44]$, respectively. The presence of the $\mathrm{O}-\mathrm{H}$ and $\mathrm{N}-\mathrm{H}$ groups makes the CDs hydrophilic and improves the stability and dispersibility of the $\mathrm{CDs}$ in aqueous solutions. In addition, there are $-\mathrm{N}=\mathrm{C}=\mathrm{N}$, $\mathrm{N}=\mathrm{C}=\mathrm{O}$ stretching vibrations represented by the weak bonds at 2156 and $2023 \mathrm{~cm}^{-1}$ for the HTC-CDs and 2155 and $2063 \mathrm{~cm}^{-1}$ for the LA-CDs- $10 \%$ [45]. The $\mathrm{C}-\mathrm{H}$ stretching vibrations are at 2931 and $2875 \mathrm{~cm}^{-1}$, respectively [7]. The stretching bonds of the $\mathrm{C}=\mathrm{O} / \mathrm{C}=\mathrm{C}$ bond are around 1706 and $1670 \mathrm{~cm}^{-1}$, respectively [46], and the $\mathrm{CH}_{3}$ bending vibrations are at 1375 and $1389 \mathrm{~cm}^{-1}$, respectively [38]. The stretching bonds of the C-N/ $\mathrm{C}-\mathrm{O}$ bond are at 1096 and $1117 \mathrm{~cm}^{-1}$ for the HTC-CDs and the LA-CDs- $10 \%$, respectively [38,44]. Also, there are weak bonds in the range of $800-600 \mathrm{~cm}^{-1}$, corresponding to the bending vibrations of $\mathrm{C}-\mathrm{O}$ and $\mathrm{C}-\mathrm{N}$ bonds. Note that the FTIR spectra of all the LA-CDs- $\mathrm{x} \%$ reveal the presence of N-containing groups, as shown in Figure S3f in Supporting Information File 1, suggesting that the LAL processing of the annealed-HTC carbon particles introduced $\mathrm{N}$-based functional groups on the surface of the CDs.

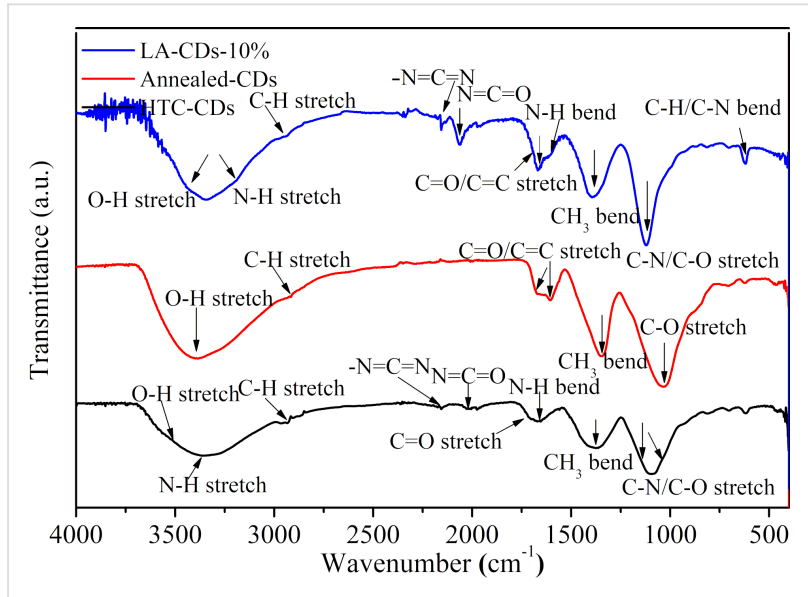

Figure 7: FTIR spectra of soybean-derived carbon nanoparticles.

In contrast to the HTC-CDs and the LA-CDs- $\mathrm{x} \%$, the FTIR spectrum of the annealed-CDs does not have peaks in the range of $2165-2115 \mathrm{~cm}^{-1}$ and $2115-1988 \mathrm{~cm}^{-1}$, which are associated with the presence of nitrogen. Such a difference reveals the importance of nitrogen in controlling the PL characteristics of the soybean-derived CDs. It is the N-containing functional groups that determine the PL behavior of both the HTC-CDs and LA-CDs- $\mathrm{x} \%$. Note that there is a new peak around $1600 \mathrm{~cm}^{-1}$ for the annealed-CDs, which is attributed to aromatic $\mathrm{C}=\mathrm{C}$ ring bond $[47,48]$. 
As discussed above, the PL characteristics of the soybeanderived CDs are dependent on the surface-functional groups. XPS analysis was performed to determine the chemical states of elements on the surface of the soybean-derived C-dots. Figure 8 depicts the XPS spectra of the soybean-derived CDs. Table S1 in Supporting Information File 1 lists the chemical compositions on the surface of the soybean-derived CDs, as determined from the XPS analysis. Both the HTC-CDs and LA-CDs- $10 \%$ contain the elements $\mathrm{C}, \mathrm{N}$ and $\mathrm{O}: 10.3 \%$ of $\mathrm{N}, 16.1 \%$ of $\mathrm{O}$ and $73.6 \%$ of $\mathrm{C}$ in the HTC-CDs and $4.4 \%$ of $\mathrm{N}, 44.5 \%$ of $\mathrm{O}$ and $51.1 \%$ of $\mathrm{C}$ in the LA-CDs- $10 \%$. The ratios of $\mathrm{N}$ to $\mathrm{C}$ and $\mathrm{O}$ to $\mathrm{C}$ are 0.14 and 0.08 , respectively, for the HTC-CDs and 0.09 and 0.87 , respectively, for the LA-CDs- $10 \%$. The HTC-CDs are relatively N-rich, and the LA-CDs- $10 \%$ are O-rich. The differences in the fractions of oxygen and nitrogen likely suggest that the two kinds of the CDs might possess different surface-functional groups, leading to the distinct PL responses under UV-vis irradiation. According to Figure 8a and Table S1 in Supporting Information File 1, there is no nitrogen present in the annealed-CDs, in accord with the FTIR measurement shown in Figure 7. This result confirms again the important role of nitrogen in the PL response of the soybean-derived CDs.

Figure $8 \mathrm{~b}-\mathrm{f}$ shows the deconvoluted high-resolution spectra of $\mathrm{O} 1 \mathrm{~s}, \mathrm{~N} 1 \mathrm{~s}$ and $\mathrm{C} 1 \mathrm{~s}$ in the soybean-derived CDs. The binding energies of $\mathrm{O} 1 \mathrm{~s}$ are 532, 533, and $533 \mathrm{eV}$ for the HTC-CDs, annealed-CDs and LA-CDs- $10 \%$, respectively, which are deconvoluted to $\mathrm{C}-\mathrm{O}$ and $\mathrm{C}=\mathrm{O}$ bonds. For the HTC-CDs, the binding energies of $\mathrm{N} 1 \mathrm{~s}$ determined from the deconvoluted high-resolution spectrum of $\mathrm{N} 1 \mathrm{~s}$ are 398.1, 399.3, 401.5, and $402.1 \mathrm{eV}$, which are assigned to pyridinic, amine, pyrrolic and graphitic nitrogen, respectively [49,50]. For the LA-CDs-10\%, the binding energies of the corresponding $\mathrm{N}$ 1s are 398.7, 399.6, 401.0 and $402.1 \mathrm{eV}$, respectively. Thus, both of the HTC-CDs and the LA-CDs- $10 \%$ likely possess the same types of surfacefunctional groups but with different fractions. The difference in the fractions of the surface-functional groups leads to different PL characteristics.

For the HTC-CDs, the binding energies of $\mathrm{C} 1 \mathrm{~s}$ are measured to be $285.1,286.2,287.8$, and $289.3 \mathrm{eV}$, which are assigned to the $\mathrm{C}-\mathrm{C} / \mathrm{C}=\mathrm{C}\left(\mathrm{sp}^{3}\right.$ and $\left.\mathrm{sp}^{2}\right), \mathrm{C}-\mathrm{N}\left(\mathrm{sp}^{3}\right), \mathrm{C}=\mathrm{O}$, and $\mathrm{O}-\mathrm{C}=\mathrm{O}\left(\mathrm{sp}^{2}\right)$, respectively $[20,38,51,52]$. The binding energies of $\mathrm{C} 1 \mathrm{~s}$ in the annealed-CDs are 285.6, 286.7, 287.9 and $289.8 \mathrm{eV}$, corresponding to the $\mathrm{C}-\mathrm{C} / \mathrm{C}=\mathrm{C}, \mathrm{C}-\mathrm{O}, \mathrm{C}=\mathrm{O}$ and $\mathrm{O}-\mathrm{C}=\mathrm{O}$ groups, while the binding energies of $\mathrm{C} 1 \mathrm{~s}$ in the LA-CDs- $10 \%$, are 294.8, 293.6, 289.3, 287.4, 286.3, and $285.3 \mathrm{eV}$, corresponding to the $\mathrm{C}-\mathrm{F}_{3}, \mathrm{C}-\mathrm{F}_{2}, \mathrm{O}-\mathrm{C}=\mathrm{C}, \mathrm{C}=\mathrm{O}, \mathrm{C}-\mathrm{N}$, and $\mathrm{C}-\mathrm{C} / \mathrm{C}=\mathrm{C}$ groups, respectively [53]. The presence of the $\mathrm{C}-\mathrm{F}_{3}$ bond in the LA-CDs- $10 \%$ was from the Teflon binder used for the LAL processing. Note that the Teflon binder has no effect on the emission, as revealed in Figure S5 in Supporting Information File 1. According to Figure S5, the sharp peaks in the photoluminescence spectrum are from the water Raman scattering. The broad peaks of the emissions at 418, 422 and $436 \mathrm{~nm}$ have much weaker intensities than the water Raman scattering,
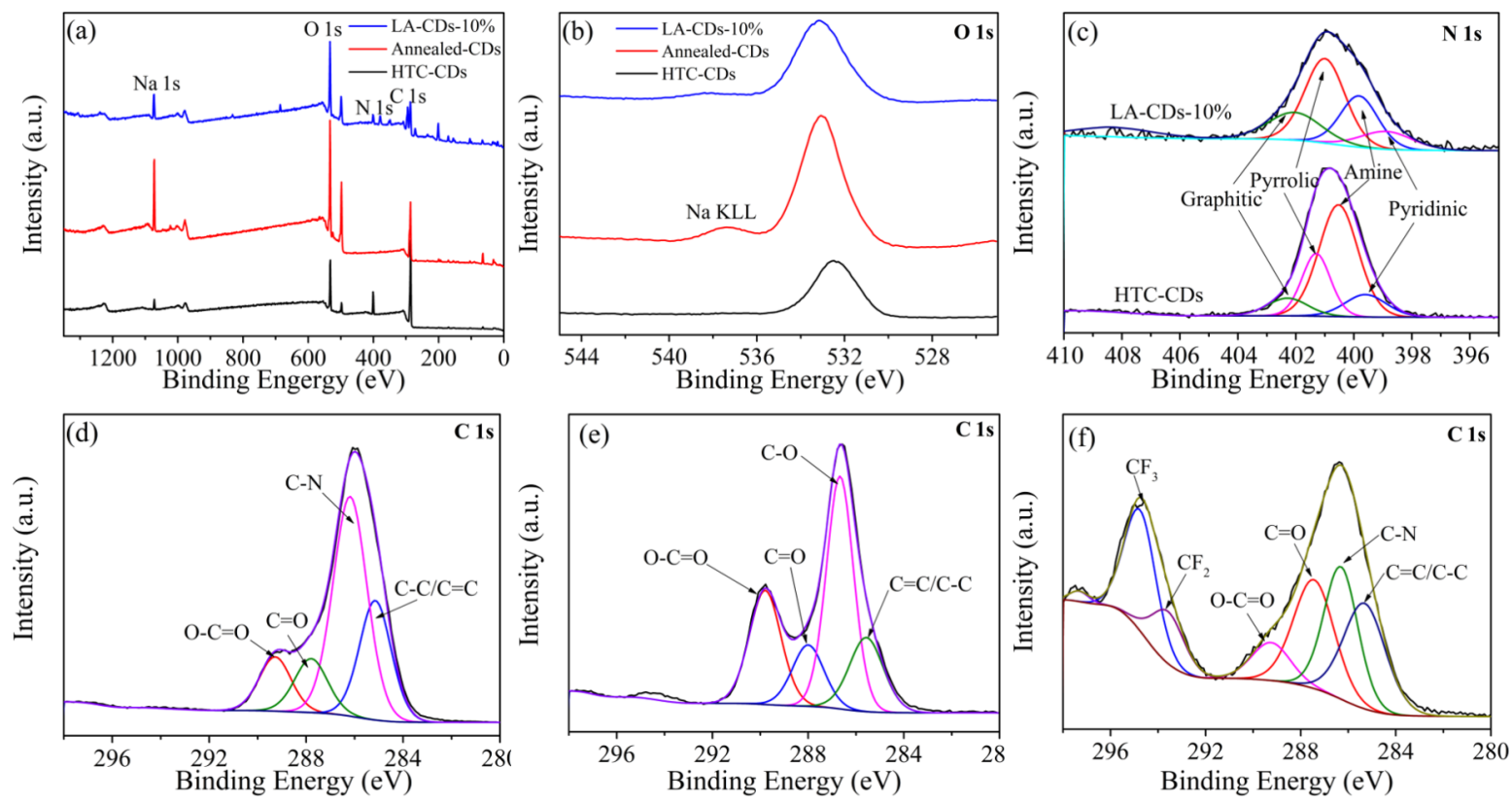

Figure 8: (a) XPS survey spectra, (b) deconvoluted high-resolution spectra of $\mathrm{O} 1 \mathrm{~s}$, (c) deconvoluted high-resolution spectra of $\mathrm{N}$ 1s; and deconvoluted high-resolution spectra of C 1 s of (d) HTC-CDs, (e) annealed-CDs, and (f) LA-CDs- $10 \%$. 
suggesting that the PL intensity from laser-ablated Teflon is negligible. Thus, both the HTC-CDs and the LA-CDs-10\% possessed $\mathrm{C}-\mathrm{N}$ groups, which contributed to the PL response under UV excitation.

Additional peaks at 1074.3, 687.1, 533.1, 400.8 and $286.4 \mathrm{eV}$ in the XPS spectrum of the LA-CDs- $10 \%$ are attributed to $\mathrm{Na} 1 \mathrm{~s}$, $\mathrm{F} 1 \mathrm{~s}, \mathrm{O} 1 \mathrm{~s}, \mathrm{~N} 1 \mathrm{~s}$ and $\mathrm{C} 1 \mathrm{~s}$. The presence of the $\mathrm{Na} 1 \mathrm{~s}$ peak was due to the sodium residual present in the glassware.

The XPS analyses of the LA-CDs- $\mathrm{x} \%$ were also performed, as shown in Figures S2 and S3 and summarized in Tables S2 and $\mathrm{S} 3$ in Supporting Information File 1. Similar to the LA-CDs$10 \%$, all the other LA-CDs- $\mathrm{x} \%$ exhibited a strong $\mathrm{N} 1 \mathrm{~s}$ peak in the range of 400-402 eV, corresponding to the graphitic, pyrrolic, amine and pyridinic nitrogen. All these results suggest that the LAL processing of the annealed-HTC carbon particles in $\mathrm{NH}_{4} \mathrm{OH}$ solutions is an effective method for doping $\mathrm{N}$ into carbon nanoparticles, and the amount of doped $\mathrm{N}$ can be simply controlled by the concentration of the $\mathrm{NH}_{4} \mathrm{OH}$ solution.

According to Figure 4a,b, the PL decay exists for the 440 and $450 \mathrm{~nm}$ emissions of the HTC-CDs and LA-CDs- $10 \%$, respectively, under $393 \mathrm{~nm}$ excitation. Fitting the data to a tripleexponential function, we determined the lifetimes for the corresponding rate processes and the relative contributions, as listed in Table 1.

For the HTC-CDs, the strongest emission is at the wavelength of $440 \mathrm{~nm}$. The lifetime of the intrinsic state $\left(\tau_{1}\right)$ at $440 \mathrm{~nm}$ emssion was $1.21 \mathrm{~ns}$ with a relative contribution of $28.6 \%$. The lifetimes and the relative contributions of the intrinsic state $\left(\tau_{1}\right)$ are (1.05 ns, $24.4 \%)$ and (1.14 ns, 24.6\%) for emission at longer wavelengths of 452 and $459 \mathrm{~nm}$, respectively. For the $440 \mathrm{~nm}$ emission, the lifetimes and the relative contributions of the surface-functional groups $\left(\tau_{1}\right.$ and $\left.\tau_{2}\right)$ are $(4.24 \mathrm{~ns}, 52.8 \%)$ and $(15.0 \mathrm{~ns}, 18.6 \%)$, respectively; for the 452 and $459 \mathrm{~nm}$ emissions, the lifetimes and the relative contributions of the surfacefunctional groups are ((4.23 ns, 55.0\%), (13.6 ns, 20.6\%)) and ((4.41 ns, 55.1\%), (14.0 ns, 20.3\%)), respectively. It is evident that the surface-functional groups played a dominant role in determining the lifetime of the PL response of the HTC-CDs [54]

From Table 1, we note that the strongest emission for the LA-CDs- $10 \%$ is present at $459 \mathrm{~nm}$, and the lifetimes for the intrinsic state and the surface-functional groups are generally lower than those for the HTC-CDs under UV excitation of the same wavelengths. On the other hand, the relative contributions of the surface-functional groups are larger than those for the HTC-CDs. That is to say, there is more contribution from the surface-functional groups in the LA-CDs- $10 \%$ than those in the
HTC-CDs. The LAL processing of the annealed-CDs likely increases the fraction of the surface-functional groups responsible for the PL response of the soybean-derived CDs.

According to the above discussion, we can conclude that the $\mathrm{N}$-containing functional groups play the key role in determining the PL response of the soybean-derived CDs. The LAL processing of the annealed-HTC carbon particles in the $\mathrm{NH}_{4} \mathrm{OH}$ solution successfully introduced the surface-functional groups with nitrogen to the CDs, and all the LA-CDs- $\mathrm{x} \%$ exhibited PL emission under UV excitation over a wide range of wavelengths. Under $390 \mathrm{~nm}$ excitation, the wavelengths corresponding to the maximum emission peaks are $464,459,463,462$, and $454 \mathrm{~nm}$ respectively for the LA-CDs-5\%, LA-CDs-10\%, LA-CDs- $15 \%$, LA-CDs-20\% and LA-CDs-30\% (Figure S4, Supporting Information File 1). There is no significant difference in the wavelengths corresponding to the maximum emission peaks. However, there exists a dependence of the QY of the PL emission on the fraction/amount of nitrogen.

Figure 9 shows the variations in the atomic fraction of $\mathrm{N}$ and QY of the LA-CDs- $\mathrm{x} \%$ with the concentration of $\mathrm{NH}_{4} \mathrm{OH}$. Both the atomic fraction of $\mathrm{N}$ and $\mathrm{QY}$ of the LA-CDs- $\mathrm{x} \%$ increase first with increasing concentration of $\mathrm{NH}_{4} \mathrm{OH}$, then reach the maximum, and then decrease with increasing concentration of $\mathrm{NH}_{4} \mathrm{OH}$. In general, the QY of the LA-CDs- $\mathrm{x} \%$ is a function of the fraction/amount of nitrogen, which is consistent with the results reported in the literature [54]. There exists a maximum fraction of nitrogen, which can be introduced through the LA-activated surface-functional groups to the annealed-CDs. Note that the deviation of the QY trend from that of the $\mathrm{N}$-atomic fraction at high $\mathrm{N}$ content implies that other factors (i.e., defects) may start to influence the PL response of the LA-CDs- $x \%$ with $x \geq 30 \%$.

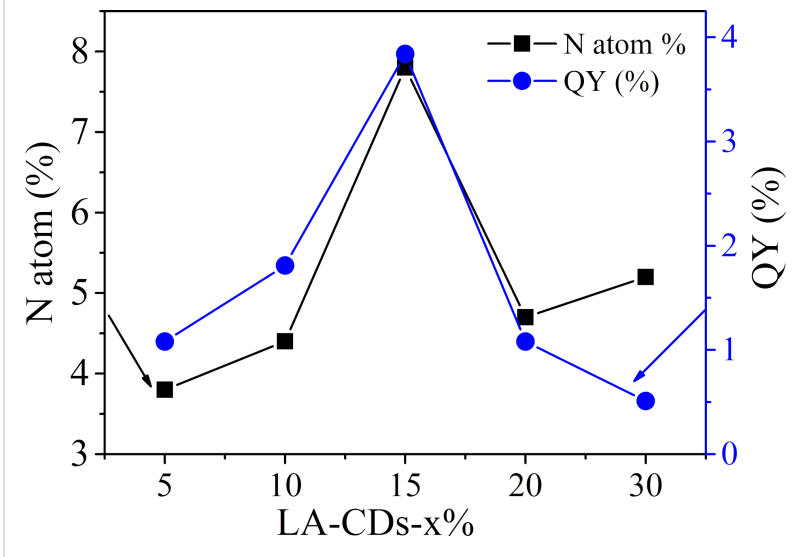

Figure 9: Variations of atomic fraction of $\mathrm{N}$ and $\mathrm{QY}$ of LA-CDs- $\mathrm{x} \%$ with the concentration of $\mathrm{NH}_{4} \mathrm{OH}$. 
Table 3 summarizes the PL characteristics of the soybeanderived CDs. For comparison, the results obtained by Xu et al. [31] and Meng et al. [32] are also included in Table 3. In general, all the soybean-derived CDs exhibited different PL characteristics, as revealed by the difference in the wavelength of the maximum emission for different excitations. The QYs of the soybean-derived CDs obtained in this work are comparable to the result given by $\mathrm{Xu}$ et al. [31] and smaller than the result given by Meng et al. [32]. All of these works reveal the important role of the structure (surface state and molecular state) of the soybean-derived CDs, which is dependent on the carbonization process and the processing parameters, in controlling the optical properties of the biomass-derived CDs.

\section{Conclusion}

In summary, we have synthesized carbon nanoparticles with different PL characteristics from the ground soybean residual via the combination of hydrothermal carbonization, annealing at high temperature and laser ablation in $\mathrm{NH}_{4} \mathrm{OH}$ solution. The annealing of the soybean-derived carbon particles at high temperature damaged/destroyed the surface structures of carbon nanoparticles, removed the nitrogen-containing surface functional groups, and resulted in the loss of the PL characteristics. The laser ablation of the annealed soybean-derived carbon particles in the $\mathrm{NH}_{4} \mathrm{OH}$ solutions introduced $\mathrm{N}$-containing surfacefunctional groups on the carbon nanoparticles.

Both the HTC-CDs and the LA-CDs- $\mathrm{x} \%$ exihibited PL characteristics under UV-vis excitation due to the presence of N-containing surface-functional groups, even though the PL response under UV excitation of the same wavelength was different. The difference in the PL response can be attribued to different amounts of $\mathrm{N}$-containing surface-functional groups, even though both of the soybean-derived nanoparticles possessed similar types of surface-functional groups.

The results presented in this work reveal the important role of the surface-functional groups in controlling the PL response of
CDs and shed insight into the PL mechanisms of the CDs with $\mathrm{N}$-containing surface-functional groups. This work offers a simple, green, and effective strategy for the surface N-functionalization of carbon nanoparticles derived from biomass and biowaste and for the production of carbon nanoparticles with stable PL characteristics and excellent water-wettability.

\section{Supporting Information}

\section{Supporting Information File 1}

Additional experimental data.

[https://www.beilstein-journals.org/bjnano/content/ supplementary/2190-4286-11-48-S1.pdf]

\section{Funding}

This work is supported by the National Science Foundation (NSF) through the grant CMMI-1634540 and CMMI-1854554 (FQY) monitored by Dr. Khershed Cooper, the grant CHE1800316 (DSY) of the Division of Chemistry, and the National Natural Science Foundation of China (No. 21805123) (WS).

\section{ORCID ${ }^{\circledR}$ iDs}

Dong-sheng Yang - https://orcid.org/0000-0001-9842-4343

Fuqian Yang - https://orcid.org/0000-0001-6277-3082

\section{Preprint}

A non-peer-reviewed version of this article has been previously published as a preprint doi:10.3762/bxiv.2019.139.v1

\section{References}

1. Demchenko, A. P.; Dekaliuk, M. O. Methods Appl. Fluoresc. 2013, 1, 042001. doi:10.1088/2050-6120/1/4/042001

2. Qu, K.; Wang, J.; Ren, J.; Qu, X. Chem. - Eur. J. 2013, 19, 7243-7249. doi:10.1002/chem.201300042

3. Yang, S.-T.; Wang, X.; Wang, H.; Lu, F.; Luo, P. G.; Cao, L.; Meziani, M. J.; Liu, J.-H.; Liu, Y.; Chen, M.; Huang, Y.; Sun, Y.-P. J. Phys. Chem. C 2009, 113, 18110-18114. doi:10.1021/jp9085969

\begin{tabular}{|c|c|c|c|c|c|c|}
\hline $\begin{array}{l}\text { Processing } \\
\text { method }\end{array}$ & Temperature $\left({ }^{\circ} \mathrm{C}\right)$ & Agent & Time (h) & $\begin{array}{l}\text { Maximum } \\
\text { emission/excitation } \\
\text { wavelength }\end{array}$ & $\begin{array}{l}\text { Atomic fraction of } \mathrm{C}, \mathrm{O} \\
\text { and } \mathrm{N}(\%)\end{array}$ & QY (\%) \\
\hline $\begin{array}{l}\text { HTC-CDs } \\
\text { (this work) }\end{array}$ & 200 & $\begin{array}{l}1 \text { wt \% } \\
\mathrm{H}_{2} \mathrm{SO}_{4}\end{array}$ & 2 & $440 / 360$ & 73.6/16.1/10.3 & 4.46 \\
\hline $\begin{array}{l}\text { annealed-CDs } \\
\text { (this work) }\end{array}$ & 850 & argon & 2 & $\mathrm{~N} / \mathrm{A}$ & $60.0 / 40.0 / 0.0$ & $\mathrm{~N} / \mathrm{A}$ \\
\hline $\begin{array}{l}\text { LA-CDs } \\
\text { (this work) }\end{array}$ & 25 & $\begin{array}{l}15 \mathrm{vol} \% \\
\mathrm{NH}_{4} \mathrm{OH}\end{array}$ & 1 & $459 / 390$ & $54.7 / 37.5 / 7.8$ & 3.84 \\
\hline pyrolysis [31] & 200 & argon & 3 & $405 / 330$ & $81.28 / 15.92 / 2.49$ & 3.17 \\
\hline HTC [32] & 170 & DI water & 16 & $\approx 533 / 470$ & $46.27 / \approx / \approx$ & 7.14 \\
\hline
\end{tabular}


4. Wang, W.; Li, Y.; Cheng, L.; Cao, Z.; Liu, W. J. Mater. Chem. B 2014 2, 46-48. doi:10.1039/c3tb21370f

5. Kruss, S.; Hilmer, A. J.; Zhang, J.; Reuel, N. F.; Mu, B.; Strano, M. S. Adv. Drug Delivery Rev. 2013, 65, 1933-1950. doi:10.1016/j.addr.2013.07.015

6. Sun, Y.-P.; Zhou, B.; Lin, Y.; Wang, W.; Fernando, K. A. S.; Pathak, P.; Meziani, M. J.; Harruff, B. A.; Wang, X.; Wang, H.; Luo, P. G.; Yang, H.; Kose, M. E.; Chen, B.; Veca, L. M.; Xie, S.-Y. J. Am. Chem. Soc. 2006, 128, 7756-7757. doi:10.1021/ja062677d

7. Jiang, K.; Sun, S.; Zhang, L.; Lu, Y.; Wu, A.; Cai, C.; Lin, H. Angew. Chem., Int. Ed. 2015, 54, 5360-5363. doi:10.1002/anie.201501193

8. Tan, M.; Zhang, L.; Tang, R.; Song, X.; Li, Y.; Wu, H.; Wang, Y.; Lv, G.; Liu, W.; Ma, X. Talanta 2013, 115, 950-956. doi:10.1016/j.talanta.2013.06.061

9. Sun, X.; He, J.; Meng, Y.; Zhang, L.; Zhang, S.; Ma, X.; Dey, S.; Zhao, J.; Lei, Y. J. Mater. Chem. A 2016, 4, 4161-4171. doi:10.1039/c5ta10027e

10. Zhu, C.; Zhai, J.; Dong, S. Chem. Commun. 2012, 48, 9367-9369. doi:10.1039/c2cc33844k

11. Cui, X.; Wang, Y.; Liu, J.; Yang, Q.; Zhang, B.; Gao, Y.; Wang, Y.; Lu, G. Sens. Actuators, B 2017, 242, 1272-1280. doi:10.1016/.j.snb.2016.09.032

12. Chen, X.; Kis, A.; Zettl, A.; Bertozzi, C. R. Proc. Natl. Acad. Sci. U. S. A. 2007, 104, 8218-8222. doi:10.1073/pnas.0700567104

13. Cao, L.; Yang, S.-T.; Wang, X.; Luo, P. G.; Liu, J.-H.; Sahu, S.; Liu, Y.; Sun, Y.-P. Theranostics 2012, 2, 295-301. doi:10.7150/thno.3912

14. Qiao, Z.-A.; Wang, Y.; Gao, Y.; Li, H.; Dai, T.; Liu, Y.; Huo, Q. Chem. Commun. 2010, 46, 8812-8814. doi:10.1039/c0cc02724c

15. Liu, Y.; Kim, D. Y. Chem. Commun. 2015, 51, 4176-4179. doi:10.1039/c4cc07618d

16. Chen, G. X.; Hong, M. H.; Chong, T. C.; Elim, H. I.; Ma, G. H.; Ji, W. J. Appl. Phys. 2004, 95, 1455-1459. doi:10.1063/1.1637933

17. Lai, C.-W.; Hsiao, Y.-H.; Peng, Y.-K.; Chou, P.-T. J. Mater. Chem. 2012, 22, 14403-14409. doi:10.1039/c2jm32206d

18. Wang, C.; Xu, Z.; Cheng, H.; Lin, H.; Humphrey, M. G.; Zhang, C. Carbon 2015, 82, 87-95. doi:10.1016/j.carbon.2014.10.035

19. Sevilla, M.; Fuertes, A. B. Chem. - Eur. J. 2009, 15, 4195-4203. doi:10.1002/chem.200802097

20. Yang, Y.; Cui, J.; Zheng, M.; Hu, C.; Tan, S.; Xiao, Y.; Yang, Q.; Liu, Y. Chem. Commun. 2012, 48, 380-382. doi:10.1039/c1cc15678k

21. Sahu, S.; Behera, B.; Maiti, T. K.; Mohapatra, S. Chem. Commun. 2012, 48, 8835-8837. doi:10.1039/c2cc33796g

22. Liu, S.; Tian, J.; Wang, L.; Zhang, Y.; Qin, X.; Luo, Y.; Asiri, A. M.; Al-Youbi, A. O.; Sun, X. Adv. Mater. (Weinheim, Ger.) 2012, 24, 2037-2041. doi:10.1002/adma.201200164

23.Zeng, H.; Du, X.-W.; Singh, S. C.; Kulinich, S. A.; Yang, S.; He, J.; Cai, W. Adv. Funct. Mater. 2012, 22, 1333-1353. doi:10.1002/adfm.201102295

24. Liu, P.; Cui, H.; Wang, C. X.; Yang, G. W. Phys. Chem. Chem. Phys. 2010, 12, 3942-3952. doi:10.1039/b918759f

25. Amendola, V.; Meneghetti, M. Phys. Chem. Chem. Phys. 2013, 15, 3027-3046. doi:10.1039/c2cp42895d

26. Yang, L.; May, P. W.; Yin, L.; Smith, J. A.; Rosser, K. N. Diamond Relat. Mater. 2007, 16, 725-729. doi:10.1016/j.diamond.2006.11.010

27. Li, Z. F.; Yang, Z. Y.; Xiao, R. F. Appl. Phys. A: Mater. Sci. Process. 1996, 63, 243-246. doi:10.1007/bf01567876
28. Baker, S. N.; Baker, G. A. Angew. Chem., Int. Ed. 2010, 49, 6726-6744. doi:10.1002/anie.200906623

29. Zhu, S.; Song, Y.; Zhao, X.; Shao, J.; Zhang, J.; Yang, B. Nano Res. 2015, 8, 355-381. doi:10.1007/s12274-014-0644-3

30. Sun, X.; Lei, Y. TrAC, Trends Anal. Chem. 2017, 89, 163-180. doi:10.1016/j.trac.2017.02.001

31. Xu, M.; Huang, Q.; Sun, R.; Wang, X. RSC Adv. 2016, 6, 88674-88682. doi:10.1039/c6ra18725k

32. Meng, Y.; Zhang, Y.; Sun, W.; Wang, M.; He, B.; Chen, H.; Tang, Q. Electrochim. Acta 2017, 257, 259-266. doi:10.1016/j.electacta.2017.10.086

33. Wang, S.; Sun, W.; Yang, D.-S.; Yang, F. Mater. Today Energy 2019, 13, 50-55. doi:10.1016/j.mtener.2019.04.015

34. Xu, Y.; Wu, M.; Liu, Y.; Feng, X.-Z.; Yin, X.-B.; He, X.-W.; Zhang, Y.-K. Chem. - Eur. J. 2013, 19, 2276-2283. doi:10.1002/chem.201203641

35. Bartlett, J. S.; Voss, K. J.; Sathyendranath, S.; Vodacek, A. Appl. Opt. 1998, 37, 3324-3332. doi:10.1364/ao.37.003324

36. Jia, X.; Li, J.; Wang, E. Nanoscale 2012, 4, 5572-5575. doi:10.1039/c2nr31319g

37. Wu, Q.; Li, W.; Tan, J.; Wu, Y.; Liu, S. Chem. Eng. J. 2015, 266, 112-120. doi:10.1016/j.cej.2014.12.089

38. Calabro, R. L.; Yang, D.-S.; Kim, D. Y. J. Colloid Interface Sci. 2018, 527, 132-140. doi:10.1016/j.jcis.2018.04.113

39. Wang, H.; Sun, P.; Cong, S.; Wu, J.; Gao, L.; Wang, Y.; Dai, X.; Yi, Q.; Zou, G. Nanoscale Res. Lett. 2016, 11, 27. doi:10.1186/s11671-016-1231-1

40. Wang, L.; Zhu, S.-J.; Wang, H.-Y.; Qu, S.-N.; Zhang, Y.-L.; Zhang, J.-H.; Chen, Q.-D.; Xu, H.-L.; Han, W.; Yang, B.; Sun, H.-B. ACS Nano 2014, 8, 2541-2547. doi:10.1021/nn500368m

41. Li, X.; Wang, H.; Shimizu, Y.; Pyatenko, A.; Kawaguchi, K.; Koshizaki, N. Chem. Commun. 2011, 47, 932-934. doi:10.1039/c0cc03552a

42. Yu, P.; Wen, X.; Toh, Y.-R.; Tang, J. J. Phys. Chem. C 2012, 116 , 25552-25557. doi:10.1021/jp307308z

43. Stuart, B. Infrared Spectroscopy. Kirk-Othmer Encyclopedia of Chemical Technology; John Wiley and Sons: Hoboken, NJ, USA, 2015; pp 1-18. doi:10.1002/0471238961.0914061810151405.a01.pub3

44. Socrates, G. Infrared and Raman Characteristic Group Frequencies: Tables and Charts; John Wiley \& Sons: Chichester, UK, 2004.

45. Lieber, E.; Levering, D. R.; Patterson, L. Anal. Chem. (Washington, DC, U. S.) 1951, 23, 1594-1604. doi:10.1021/ac60059a021

46. Camacho, N. P.; West, P.; Torzilli, P. A.; Mendelsohn, R. Biopolymers 2001, 62, 1-8. doi:10.1002/1097-0282(2001)62:1<1::aid-bip10>3.0.co;2-o

47. Pavia, D. L.; Lampman, G. M.; Kriz, G. S.; Vyvyan, J. A. Introduction to Spectroscopy; Cengage Learning, 2008.

48. Hirschfeld, T.; Chase, B. Appl. Spectrosc. 1986, 40, 133-137. doi:10.1366/0003702864509538

49. Mohtasebi, A.; Chowdhury, T.; Hsu, L. H. H.; Biesinger, M. C.; Kruse, P. J. Phys. Chem. C 2016, 120, 29248-29263. doi:10.1021/acs.jpcc.6b09950

50. Wahid, M.; Parte, G.; Phase, D.; Ogale, S. J. Mater. Chem. A 2015, 3 , 1208-1215. doi:10.1039/c4ta06068g

51. Li, X.; Zhang, S.; Kulinich, S. A.; Liu, Y.; Zeng, H. Sci. Rep. 2015, 4, 4976. doi:10.1038/srep04976

52. Lu, S.; Cong, R.; Zhu, S.; Zhao, X.; Liu, J.; Tse, J. S.; Meng, S.; Yang, B. ACS Appl. Mater. Interfaces 2016, 8, 4062-4068. doi:10.1021/acsami.5b11579 
53. Yang, Z.; Xu, M.; Liu, Y.; He, F.; Gao, F.; Su, Y.; Wei, H.; Zhang, Y. Nanoscale 2014, 6, 1890-1895. doi:10.1039/c3nr05380f

54. Calabro, R. L.; Yang, D.-S.; Kim, D. Y. ACS Appl. Nano Mater. 2019, 2, 6948-6959. doi:10.1021/acsanm.9b01433

\section{License and Terms}

This is an Open Access article under the terms of the Creative Commons Attribution License

(http://creativecommons.org/licenses/by/4.0). Please note that the reuse, redistribution and reproduction in particular requires that the authors and source are credited.

The license is subject to the Beilstein Journal of

Nanotechnology terms and conditions:

(https://www.beilstein-journals.org/bjnano)

The definitive version of this article is the electronic one which can be found at:

doi:10.3762/bjnano. 11.48 